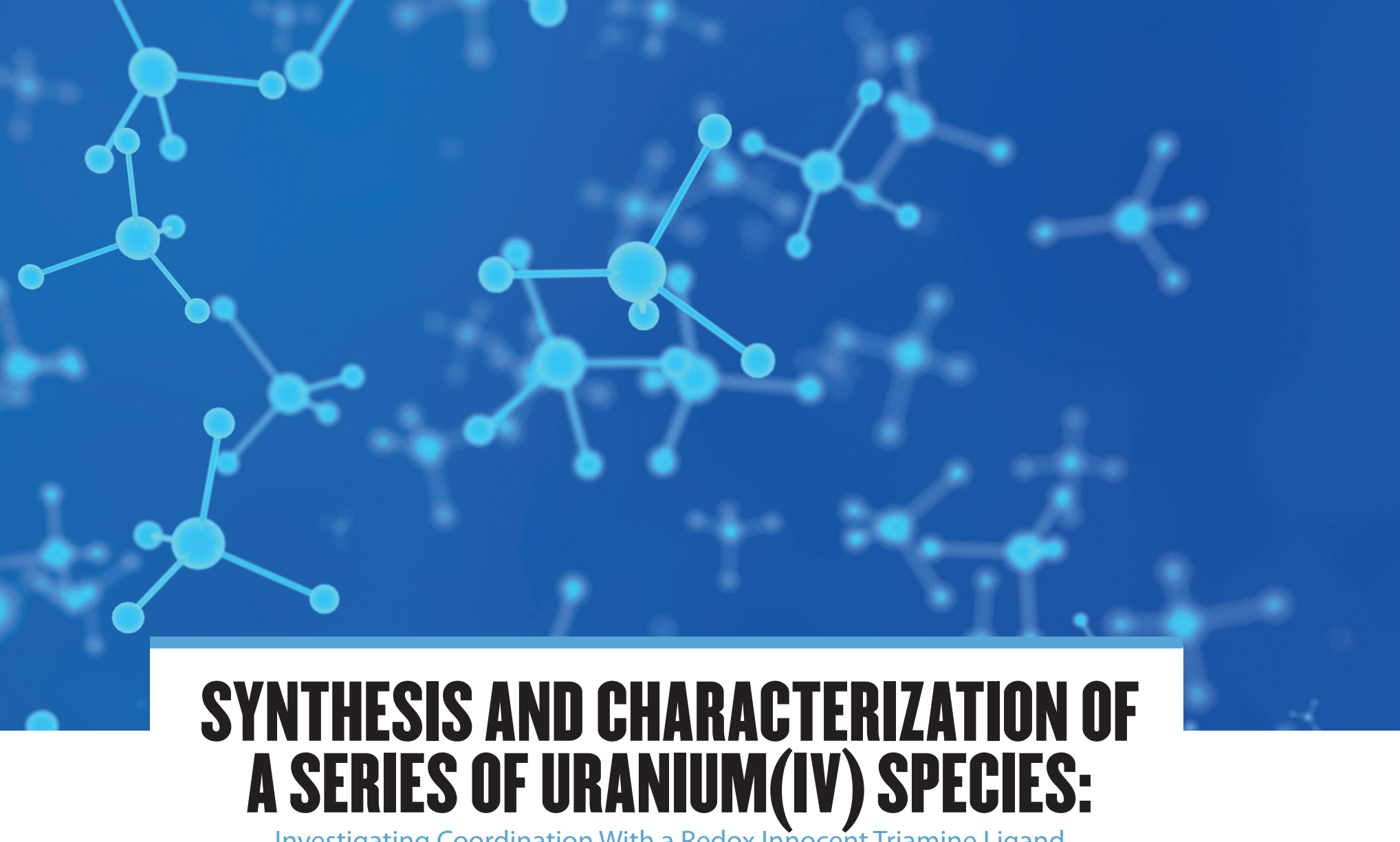

Investigating Coordination With a Redox Innocent Triamine Ligand

\title{
Student Author
}

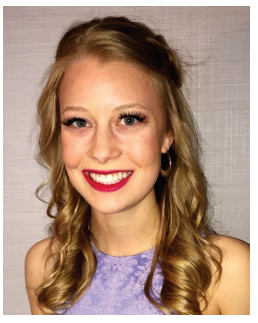

Selena L. Staun earned a BS degree in chemistry with a minor in sociology in May 2016; she graduated with department honors. She will start graduate school to pursue a $\mathrm{PhD}$ in chemistry beginning September 2016 at the University of California, Santa

Barbara. While at Purdue, Staun was an undergraduate researcher in the Bart Laboratory for over 2 years and received Purdue's Department of Chemistry 2015 Summer Research Award. She also found time to facilitate student learning as a Supplemental Instruction Leader for a math course and as a teaching assistant for a biology lab.

\section{Mentors}

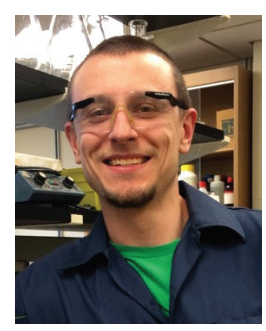

John J. Kiernicki earned AB degrees in chemistry and history from Ripon College in 2011 and is currently working on his $\mathrm{PhD}$ in inorganic chemistry at Purdue University. His current research project involves the synthesis and reactivity of low-valent uranium complexes containing redox-active ligands, and studies in the reductive silylation of the $\mathrm{UO}_{2}^{2+}$ cation.

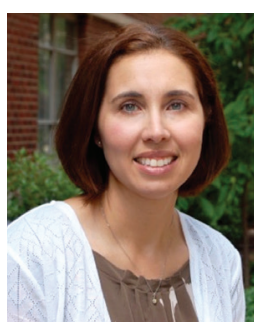

Suzanne Bart graduated from the University of Delaware with a BS in chemistry (2001) and earned her $\mathrm{PhD}$ from Cornell University with Professor Paul J. Chirik (2006). Subsequently, she was an Alexander von Humboldt Postdoctoral Fellow at the Friedrich-Alexander University Erlangen-Nuremberg under the direction of Professor Karsten Meyer. In 2008 she became an assistant professor at Purdue University, then in 2014 she was promoted to associate professor. Her research interests include organometallic transformations mediated by organoactinide species. Bart recently won an NSF CAREER award, and has been named a 2012 Cottrell Scholar and 2014 Organometallics Young Investigator Fellow. 


\section{Abstract}

Investigation of uranium(IV) complexes chelated by a tridentate amine, $\mathrm{H}_{3}$ RITA $\left(\mathrm{H}_{3} \mathrm{RITA}=\left(\mathrm{MesNHCH}_{2} \mathrm{CH}_{2}\right)_{2} \mathrm{NH}, \mathrm{Mes}=\right.$ 2,4,6-trimethylphenyl), has afforded novel new compounds with the potential for small molecule activation. Deprotonation of $\mathrm{H}_{3}$ RITA with two equivalents of benzyl potassium affords $\mathrm{K}_{2}$ HRITA, which upon reaction with uranium tetrachloride forms $(\mathrm{THF})_{2} \mathrm{UCl}_{2}(\mathrm{HRITA})(\mathrm{THF}=$ tetrahydrofuran$)$. The labile THF molecules are easily substituted for triphenylphosphine oxide $\left(\mathrm{OPPh}_{3}\right)$, a much stronger ligand, forming $\left(\mathrm{Ph}_{3} \mathrm{PO}\right) \mathrm{UCl}_{2}(\mathrm{HRITA})$. Installation of a cyclopentadienyl ligand, $\mathrm{Cp}^{*}$ $\left(\mathrm{Cp}^{*}=1,2,3,4,5\right.$-pentamethylcyclopentadienyl), was achieved by the metathesis of (THF) $\mathrm{UCl}_{2}$ (HRITA) with $\mathrm{KCp} *$ to form Cp*UCl(HRITA). For Cp*UCl(HRITA), full deprotonation of the RITA ligand was possible by using the strong base, methyllithium. The reaction of methyllithium with $\mathrm{Cp} * \mathrm{UCl}$ (HRITA) affords $\mathrm{Cp} * \mathrm{U}(\mathrm{RITA})\left(\mathrm{LiCl}(\mathrm{THF})_{2}\right)$ - a uranium species containing a weakly bound lithium chloride ligand. Replacement of the lithium chloride with triphenylphosphine oxide forms the neutral species, $\mathrm{Cp} * \mathrm{U}(\mathrm{RITA})\left(\mathrm{OPPh}_{3}\right)$, which contains a rare trianionic RITA ligand. All complexes have been characterized by ${ }^{1} \mathrm{H}$ NMR and IR spectroscopies, and where possible, their electronics were probed by electronic absorption spectroscopy. The molecular structures of (THF) ${ }_{2} \mathrm{UCl}_{2}$ (HRITA), ( $\left.\mathrm{Ph}_{3} \mathrm{PO}\right) \mathrm{UCl}_{2}$ (HRITA), $\mathrm{Cp} * \mathrm{UCl}(\mathrm{HRITA})$, and $\mathrm{Cp} * \mathrm{U}(\mathrm{RITA})$ $\left(\mathrm{LiCl}(\mathrm{THF})_{2}\right.$ ) were determined by single $\mathrm{X}$-ray diffraction studies.

Staun, S. L. (2016). Synthesis and characterization of a series of uranium(IV) species: Investigating coordination with a redox innocent triamine ligand. Journal of Purdue Undergraduate Research, 6, 56-63. http://dx.doi. org/10.5703/1288284316161

\section{Keywords}

organometallic, uranium, redox-chemistry, inorganic, coordination chemistry, actinides, synthesis, crystallography, ligand, spectroscopy

\section{INTRODUCTION}

Transition metals, those in the center of the periodic table, are at the heart of organometallic chemistry, a field that studies the bond breaking and bond forming of organic molecules by metal species. These important manipulations are responsible for essential processes, such as olefin polymerization, which makes materials and other consumer goods, as well as asymmetric hydrogenation, which is used to make pharmaceuticals and commodity chemicals.

The metals of the f-block, those at the bottom of the periodic table, have their own unique chemical properties. For instance, the lanthanides in the top row, often called rare earth elements, are used for making strong magnets, batteries for hybrid cars, and lasers. Those in the bottom row, the actinides, are known for their radioactivity, and have important applications in nuclear energy, medicine, and other power sources. In light of these important uses for the f-block elements, they are far less explored for organometallic chemistry than are their d-block counterparts. This is due to several reasons, including their redox properties, radioactivity, and in some cases, availability.

In our laboratory, we have been studying the organometallic chemistry of uranium. This element is naturally occurring and inexpensive, making it ideal for exploratory studies of the basic chemistry of the actinides. Its large atomic and ionic radii allow a high ligand (an organic molecule bonded to a metal) coordination number and many accessible oxidation states $(+3,+4,+5,+6)$ as compared to its transition metal counterparts. A major difference between uranium and transition metals lies in their redox chemistry. Whereas many transition metals undergo two- or multi-electron chemistry, uranium is generally unable to perform such processes due to low redox potentials between oxidation states. Thus, one-electron chemistry is generally observed. This is problematic, as two-electron chemical processes are desirable and commonly encountered in organometallic transformations performed by transition metals.

Our studies are focused on the synthesis of uranium(IV) compounds, which are chelated by an organic amine ligand. For our experiments, we made compounds that have a central uranium atom that is chelated to a tridentate amine, one that has three nitrogen atoms that are each bonded to the metal center. This ligand supports the uranium center, keeping it soluble in organic solvents. This 
ligand is known as one that is redox innocent, as it simply "hangs out" on the uranium, not involving itself in redox-chemistry with the metal center. In order to study how these uranium complexes behave, and if they can mediate bond breaking and bond forming reactions, we formed and characterized these compounds to make sure they were what we hypothesized.

\section{RESULTS AND DISCUSSION}

To begin, the redox innocent ligand, $\mathrm{H}_{3}$ RITA, was easily synthesized following literature methods. This ligand is a desirable starting point because it is easily synthesized on large scales and easily modified. Furthermore, variations of this ligand have been extensively used on transition metals and will allow for comparison of uranium compounds to their transition metal counterparts (Schrock, Lee, Liang, $\&$ Davis, 1998). The synthetic procedure follows a generic Buchwald-Hartwig cross-coupling reaction (Wolfe, Wagaw, \& Buchwald, 1996). Infrared spectroscopy was used to detect the presences of an $\mathrm{N}-\mathrm{H}$ bond, which shows an absorption at $3368 \mathrm{~cm}^{-1}$ due to the stretching of the three $\mathrm{N}-\mathrm{H}$ bonds. Additional characterization by ${ }^{1} \mathrm{H}$ NMR spectroscopy, which analyzes the presence and location of hydrogen atoms in a molecule, was also possible, and the data obtained matched that reported in the literature. The next step, which was performed in a glovebox, was the deprotonation of $\mathrm{H}_{3}$ RITA using two equivalents of the strong base benzyl potassium $\left(\mathrm{KCH}_{2} \mathrm{Ph}\right)$. In this reaction, the H's (protons) are removed by a strong base; since this reagent is very sensitive to moisture, this manipulation was performed in an inert dinitrogen atmosphere with dry solvents. Figure 1 displays the MBraun glovebox (left) and Schlenk line (right) that were commonly used for the air- and moisturesensitive reactions described.

To perform this reaction, both $\mathrm{H}_{3}$ RITA and benzyl potassium were weighed into separate vials with tetrahydrofuran solvent (THF) and frozen using liquid nitrogen. Upon thawing, the two solutions were mixed via pipette and stirred for 15 minutes. After this time, the volatiles of the reaction were removed using a strong vacuum (in vacuo) and the crude product was washed with pentane to afford the pure product, $\mathrm{K}_{2}$ HRITA, as a green solid (Scheme 1). Successful deprotonation was assessed by IR spectroscopy, which showed a significant decrease in the intensity of the N-H absorption. This is consistent with removal of two out of the three N-H moieties. Attempts at full deprotonation by removing the third proton to form $\mathrm{K}_{3}$ RITA were unsuccessful, but this was not viewed as a problem since it is likely that deprotonation of this third nitrogen could be successfully performed in a subsequent reaction.

Next, the ligand, $\mathrm{K}_{2}$ HRITA, was metallated using a common uranium(IV) starting material, $\mathrm{UCl}_{4}$. To a THF solution of $\mathrm{UCl}_{4}$ in the glovebox, $\mathrm{K}_{2}$ HRITA was added, resulting in a color change to dark green/ brown. After stirring for one hour, the volatiles were removed in vacuo. The product was extracted into diethyl ether and filtered over Celite (an inert filtering agent) to remove the insoluble byproduct, $\mathrm{KCl}$.

Washing the residue with pentane and drying afforded a green powder, assigned as (THF) ${ }_{2} \mathrm{UCl}_{2}(\mathrm{HRITA})$ (Scheme 1).

Characterization of (THF) $\mathrm{UCl}_{2}$ (HRITA) was accomplished using both IR and ${ }^{1} \mathrm{H}$ NMR spectroscopy. The IR spectrum again showed a broad $\mathrm{N}-\mathrm{H}$ stretch as before, indicating that it was
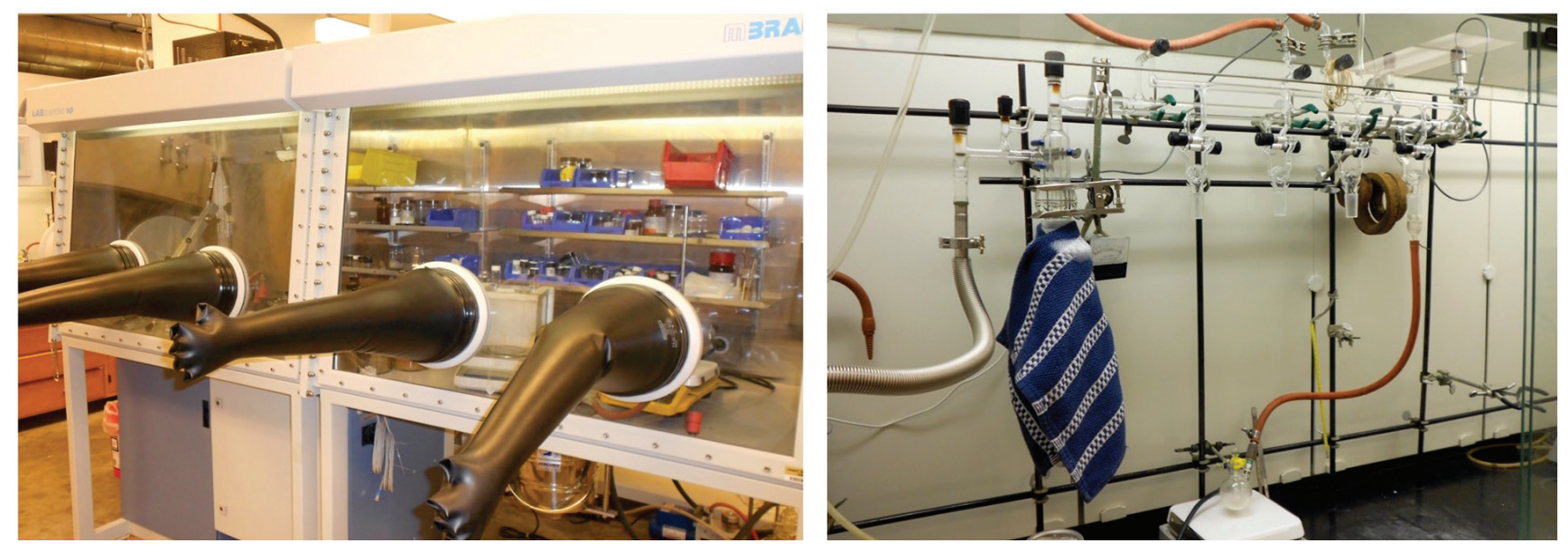

Figure 1. MBraun glovebox filled with inert $\mathrm{N}_{2}$ atmosphere (left) and Schlenk line for air- and moisture-sensitive manipulations (right). 
still present in the complex. ${ }^{1} \mathrm{H}$ NMR analysis revealed a very broad, shifted spectrum with resonances ranging from -50 to $75 \mathrm{ppm}$, indicating the presence of the uranium. The unusually large range and broadness of the resonances is due to the paramagnetic uranium center, which has two unpaired f-electrons. Additionally, the THF ligands are weakly coordinated, and their bonding and release from the uranium center also contributes to the unusual-looking nature of the spectrum. To produce a more interpretable ${ }^{1} \mathrm{H}$ NMR spectrum, triphenylphosphine oxide $\left(\mathrm{OPPh}_{3}\right)$ was added to a toluene solution (THF) $\mathrm{UCl}_{2}(\mathrm{HRITA})$ as a means of substituting the labile THF ligands. This cleanly produced $\left(\mathrm{Ph}_{3} \mathrm{PO}\right) \mathrm{UCl}_{2}$ (HRITA) (Scheme 1), which spectroscopically revealed a much sharper and interpretable ${ }^{1} \mathrm{H}$ NMR spectrum due to both the increased steric bulk of $\mathrm{OPPh}_{3}$ ligand as well as its ability to more strongly bind to uranium.

Single crystals of both (THF) $\mathrm{UCl}_{2}$ (HRITA) and $\left(\mathrm{Ph}_{3} \mathrm{PO}\right) \mathrm{UCl}_{2}$ (HRITA) were obtained from THF solutions of the complex, and analyzed using X-ray crystallography. This technique involves shooting an X-ray beam at a single crystal, and watching how the electrons of the atoms scatter (diffract) the light. Collection of the spots by a detector followed by generation of a mathematical model facilitates generation of a picture of the molecule from which structural parameters can be determined. Analysis of the data for (THF) $\mathrm{UCl}_{2}$ (HRITA) revealed the uranium complex with trans-chloride ligands (Cl1$\left.\mathrm{U} 1-\mathrm{Cl} 2=155.18(2)^{\circ}\right)$ and a tridentate HRITA ligand (Figure 2, Table 1). The uranium-chloride distances in (THF) ${ }_{2} \mathrm{UCl}_{2}$ (HRITA) (U1-Cl1 = 2.6753(7); U1-Cl2 $=2.7049(8) \AA)$ are slightly longer than those found in

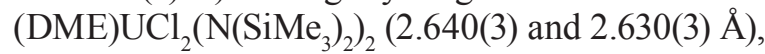
made by Templeton and colleagues (McMullough, Turner, Andersen, Zalkin, \& Templeton, 1981). For (THF) $\mathrm{UCl}_{2}$ (HRITA), two of the uranium-nitrogen distances are short (U1-N1 $=2.256(3)$ and 2.251(2) $\AA$ ), suggesting an anionic (negatively charged) bond between the $\mathrm{N}$ and the $\mathrm{U}$. These anionic uranium-nitrogen distances are slightly longer than a structurally related species made by Jantunen and colleagues (2005) $\left[\left(\left(\mathrm{ArNCH}_{2} \mathrm{CH}_{2}\right)_{2} \mathrm{O}\right) \mathrm{UCl}_{3}\right]\left[\mathrm{Li}(\mathrm{THF})_{2}\right]$ $(\mathrm{Ar}=2,6$-diisopropylphenyl), which has distances of 2.183(15) and 2.192(15) $\AA$. The middle nitrogenuranium distance in (THF) $\mathrm{UCl}_{2}$ (HRITA) is much longer $(\mathrm{U} 1-\mathrm{N} 2=2.550(2) \AA)$ and can be considered a neutral bond (using the $\mathrm{N}$ lone pair to uranium), which is supported by the fact that the hydrogen atom is still present. Analysis of the data obtained for $\left(\mathrm{Ph}_{3} \mathrm{PO}\right) \mathrm{UCl}_{2}(\mathrm{HRITA})$ revealed similar trends (Figure 2, Table 1). The uranium-chloride bonds (U1-Cl1 = 2.7033(9); U1-Cl2 = 2.6694(9) $\AA$ ) are of similar distances, while two short uranium-nitrogen $(\mathrm{U} 1-\mathrm{N} 1=2.213(3) ; \mathrm{U} 1-\mathrm{N} 3=2.230(3) \AA)$ and one long uranium-nitrogen distance (2.529(3) $\AA$ ) confirm similar coordination of the three nitrogen atoms. Evidence of stronger binding of the $\mathrm{OPPh}_{3}$ in $\left(\mathrm{Ph}_{3} \mathrm{PO}\right)$ $\mathrm{UCl}_{2}$ (HRITA) as compared to the THF molecules in (THF) ${ }_{2} \mathrm{UCl}_{2}$ (HRITA) is observed by shorter uranium-oxygen distances $(\mathrm{U} 1-\mathrm{O} 1=2.354(2)$ vs. U1$\left.\mathrm{O}_{\text {ave }}=2.625(2) \AA\right)$. The $\mathrm{U}-\mathrm{OPPh}_{3}$ distance is similar to other uranium complexes recently published by our lab, including $\left(\mathrm{Me}_{3} \mathrm{SiO}\right)_{2} \mathrm{UI}_{2}\left(\mathrm{OPPh}_{3}\right)_{2}$ (Kiernicki, Harwood, Fanwick, \& Bart, 2016).

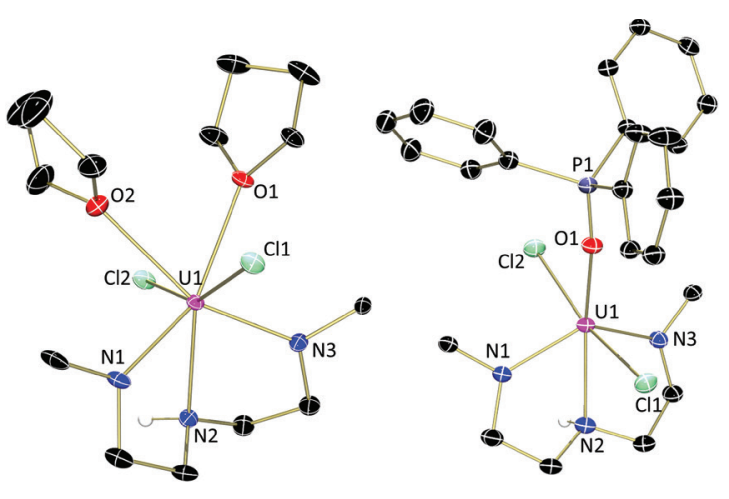

Figure 2. Molecular structures of (THF) $\mathrm{UCl}_{2}(\mathrm{HRITA})$ (left) and ( $\left.\mathrm{Ph}_{3} \mathrm{PO}\right) \mathrm{UCl}_{2}$ (HRITA) (right) displayed with $30 \%$ probability ellipsoids. 2,4,6-trimethylphenyl substituents, cocrystallized THF molecules, and hydrogen atoms not bound to nitrogen have been omitted for clarity. Black atoms indicate carbon atoms.

Next, ligand substitution of (THF) ${ }_{2} \mathrm{UCl}_{2}$ (HRITA) was accomplished by switching a chloride for a cyclopentadienyl (Cp) ligand, an aromatic fivecarbon ring. This is advantageous as this class of ligand is well known to support reactive metal centers in organometallic chemistry. A commonly used derivative has a methyl $\left(\mathrm{CH}_{3}\right)$ group bonded to each carbon. Because of its star-like appearance, this ligand is often called $\mathrm{Cp}^{*}$. In the glovebox, the potassium cyclopentadienide salt $\mathrm{KCp}^{*}$ was added to a stirring THF solution of (THF) ${ }_{2} \mathrm{UCl}_{2}$ (HRITA), which produced a color change from green to brown/orange over 2 hours. After removal of the solvent by vacuum suction, the product was extracted into diethyl ether and filtered over Celite to remove the $\mathrm{KCl}$ byproduct and afford the product, Cp*UCl(HRITA), as a dark orange powder, similar to the crust of Mars. This was done to install the $\mathrm{Cp}^{*}$ to mimic the previously synthesized complex $\mathrm{Cp} * \mathrm{U}\left({ }^{\mathrm{Mes}} \mathrm{PDI}^{\mathrm{Me}}\right)(\mathrm{THF})$. 


\begin{tabular}{|c|c|c|c|c|}
\hline Bond (Å) or Angle ( $\left(^{\circ}\right)$ & $(\mathrm{THF})_{2} \mathrm{UCl}_{2}\left(\mathrm{HN}_{3}\right)$ & $\left(\mathrm{Ph}_{3} \mathrm{PO}\right) \mathrm{UCl}_{2}\left(\mathrm{HN}_{3}\right)$ & $\mathrm{Cp} * \mathrm{UCl}\left(\mathrm{HN}_{3}\right)$ & $\mathrm{Cp} * \mathrm{U}\left(\mathrm{N}_{3}\right)\left(\mathrm{LiCl}(\mathrm{THF})_{2}\right)$ \\
\hline U1-N1 & $2.256(3)$ & $2.213(3)$ & $2.263(9)$ & $2.307(6)$ \\
\hline U1-N2 & $2.550(2)$ & $2.529(3)$ & $2.550(11)$ & $2.316(6)$ \\
\hline U1-N3 & $2.251(2)$ & $2.230(3)$ & $2.259(11)$ & $2.302(6)$ \\
\hline $\mathrm{U} 1-\mathrm{Cl} 1$ & $2.6753(7)$ & $2.7033(9)$ & $2.675(3)$ & $2.7414(16)$ \\
\hline $\mathrm{U} 1-\mathrm{Cl} 2$ & $2.7049(8)$ & $2.6694(9)$ & - & - \\
\hline U1-O1 & $2.646(2)$ & $2.354(2)$ & - & - \\
\hline $\mathrm{U} 1-\mathrm{Ct}$ & - & - & 2.523 & 2.536 \\
\hline $\mathrm{Cl} 1-\mathrm{U} 1-\mathrm{Cl} 2$ & $155.18(2)$ & 165.43(3) & - & - \\
\hline
\end{tabular}

Table 1. Bond distances and angles determined experimentally by X-ray crystallography.

Analysis of $\mathrm{Cp} * \mathrm{UCl}(\mathrm{HRITA})$ by ${ }^{1} \mathrm{H}$ NMR

spectroscopy (Figure 3) showed a spectrum similar to the starting material in that the 11 resonances were paramagnetically shifted, but in this case, they were significantly sharper than (THF) ${ }_{2} \mathrm{UCl}_{2}$ (HRITA). The largest resonance at $3.21 \mathrm{ppm}$ is assigned to the 15 equivalent protons of the $\mathrm{Cp}^{*}$ ligand. The furthest shifted and smallest resonance, $-70.99 \mathrm{ppm}$, is attributed to the $\mathrm{N}-H$ proton and is likely shifted that far because of its close proximity to the paramagnetic uranium center.

Once again, single $\mathrm{X}$-ray quality crystals of Cp*UCl(HRITA) were obtained from a concentrated diethyl ether solution and analyzed. Refinement of the data revealed the uranium center was still bound to the tridentate H(RITA) ligand (Figure 4, Table 1). Additionally, the $\mathrm{Cp}^{*}$ is bound $\eta^{5}$ to the uranium center ( $\mathrm{U} 1-\mathrm{Ct}=2.523 \AA$ ), which means that all five carbons are bound equally to the uranium, and thus the ring is acting like a halo. The uranium-chloride distance is 2.675(3) $\AA$, which is similar to the precursor (THF) ${ }_{2} \mathrm{UCl}_{2}$ (HRITA). In Cp*UCl(HRITA), two uranium-nitrogen distances are short (2.263(9) and 2.259(11) $\AA$ ), again indicating that they are anionic, while one is long (2.550(11) $\AA$ ) and is consistent with a dative interaction. The anionic uranium-nitrogen distances are similar to those found in $\mathrm{Cp}_{2}^{*} \mathrm{U}\left(\mathrm{NPh}_{2}\right) \mathrm{Cl}(2.286(5) \AA)$ synthesized by Kiplinger and colleagues (Thomson, Scott, Morris, \& Kiplinger, 2010). The N-H bond was also still apparent, which was the next focus now that $\mathrm{Cp}^{*}$ was added.

With the $\mathrm{Cp}^{*}$ attached to the ligand complex, the next step in the synthetic route was to deprotonate the $\mathrm{H}$ that is still bonded to the central N. Again, a strong base was utilized for this purpose and would need to be added with $\mathrm{Cp} * \mathrm{UCl}(\mathrm{HRITA})$ to remove the $\mathrm{H}$ atom from the central nitrogen. If this is successful,

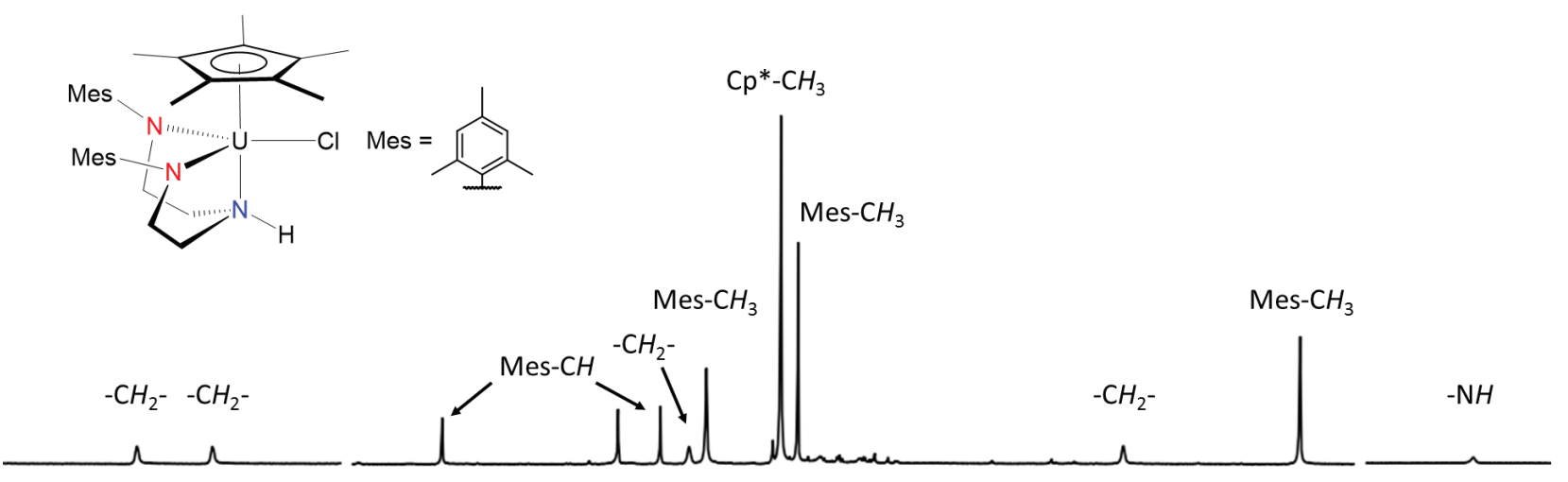

$\begin{array}{lllllllllllllllllll}57 & 55 & 53 & 51 & 12 & 10 & 8 & 6 & 4 & 2 & 0 & -2 & -4 & -6 & -8 & -10 & -70 & -72\end{array}$

Figure 3. ${ }^{1} \mathrm{H}$ NMR spectrum $\left(\mathrm{C}_{6} \mathrm{D}_{6^{\prime}} 25^{\circ} \mathrm{C}\right)$ of $\mathrm{Cp}{ }^{*} \mathrm{UCI}(\mathrm{HRITA})$. Assignment of the hydrogens are labeled above their respective resonances. 


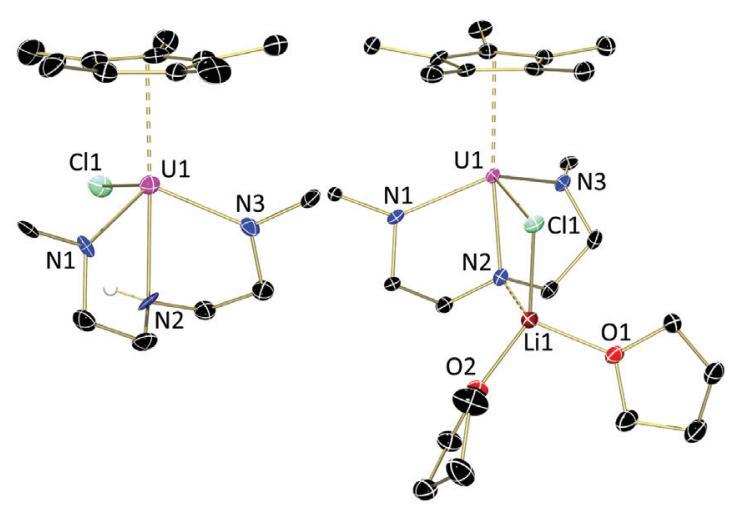

Figure 4. Molecular structures of $\mathrm{Cp}$ *UCI(HRITA) (left) and $\mathrm{Cp}^{*} \mathrm{U}(\mathrm{RITA})\left(\mathrm{LiCl}(\mathrm{THF})_{2}\right)$ (right) displayed with $30 \%$ probability ellipsoids. 2,4,6-trimethylphenyl substituents, cocrystallized THF molecules, and hydrogen atoms not bound to nitrogen have been omitted for clarity. Black atoms indicate carbon atoms.

this would convert the U-N bond from a neutral bond to an anionic one. While benzyl potassium was first attempted, it was found that this did not produce pure material, as was determined by ${ }^{1} \mathrm{H}$ NMR spectroscopy. Several other strong bases were tested, including sodium hydride, potassium tertbutoxide, and methyllithium. One must be careful when working with these bases, and they must also be handled in the glovebox. These compounds are so sensitive that even a small amount of moisture in the atmosphere can cause these to have a violent, exothermic reaction. After surveying the reagents, it was found that methyllithium (MeLi) gave the cleanest product. This reagent was previously used by Schrock and colleagues (Liang, Schrock, Davis, \& McConville, 1999) to achieve the final deprotonation of a zirconium complex bearing the same H(RITA) ligand. Thus, this reagent was used in slight excess with $\mathrm{Cp} * \mathrm{UCl}(\mathrm{HRITA})$, by stirring for $\sim 16$ hours. After removing volatiles (both solvent and methane produced in the deprotonation reaction), the product,
Cp*U(RITA)( $\mathrm{LiCl}(\mathrm{THF})_{2}$ ), was filtered with diethyl ether (Scheme 2). Characterization by ${ }^{1} \mathrm{H}$ NMR spectroscopy showed full conversion of the starting material and a clean product spectrum. The largest resonance at $12.5 \mathrm{ppm}$ is assigned to the 15 equivalent protons of the $\mathrm{Cp}^{*}$ ligand.

Single X-ray quality crystals of Cp*U(RITA) $\left(\mathrm{LiCl}(\mathrm{THF})_{2}\right.$ ) were obtained by slow diffusion of pentane into a concentrated diethyl ether solution, causing the deposition of yellow crystals. Refinement of the data revealed the uranium complex was bound to the trident ate, fully deprotonated RITA ligand (Figure 4). The X-ray structure also showed the $\mathrm{Cp}^{*}$ is bound $\eta^{5}$ to the uranium center. Also present in the structure is a molecule of $\mathrm{LiCl}$, which was not able to be separated during the reaction. The structure showed that the uranium-nitrogen bonds have been deprotonated because the bond lengths are all similar now $(\mathrm{U} 1-\mathrm{N} 1=2.307(6), \mathrm{U} 1-\mathrm{N} 2=2.316(6)$, U1$\mathrm{N} 3=2.302(6) \AA)$, and all bond lengths show that the uranium-nitrogen bonds are all anionic. The bond-distances found in $\mathrm{Cp}^{*} \mathrm{U}\left({ }^{(} \mathrm{Bu}^{-\mathrm{Mes}} \mathrm{PDI}^{\mathrm{Me}}\right)(\mathrm{THF})$, a compound made previously in our lab, showed three uranium-nitrogen bond distances slightly shorter than Cp*U(RITA)( $\left.\mathrm{LiCl}(\mathrm{THF})_{2}\right)$, but also with anionic nitrogen atoms (U1-N1 = 2.293(2), U1-N2 = 2.204(3), U1-N3 = 2.293(2) Å) (Kiernicki, Cladis, Fanwick, Zeller, \& Bart, 2015). A new LiCl(THF) ${ }_{2}$ complex formed in place of the $\mathrm{H}$ atom in $\mathrm{Cp} * \mathrm{U}$ (RITA) $\left(\mathrm{LiCl}(\mathrm{THF})_{2}\right)$, which bridges the uranium and nitrogen. This complex could be displaced easily in the presence of a donating ligand. This was proven with the addition of triphenylphosphine oxide to Cp*U(RITA)( $\mathrm{LiCl}(\mathrm{THF})_{2}$ ) in $\mathrm{C}_{6} \mathrm{D}_{6}$ (Scheme 2). While no color change was observed, a white precipitate formed, which is hypothesized to be the lithium chloride. ${ }^{1} \mathrm{H}$ NMR spectroscopic resonances assignable to free THF were observed, indicating these ligands were also displaced in favor of the strongly donating phosphine ligand. The largest

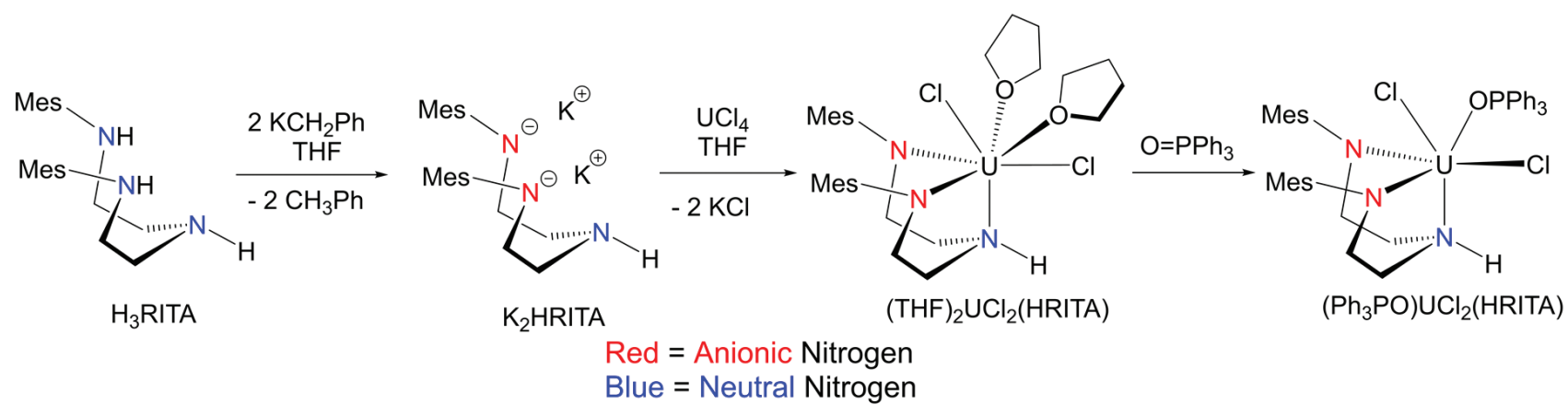

- Scheme 1. Stepwise synthesis of $(T H F)_{2} \mathrm{UCl}_{2}(\mathrm{HRITA})$ and $\left(\mathrm{Ph}_{3} \mathrm{PO}\right) \mathrm{UCl}_{2}(\mathrm{HRITA})$ from the free ligand, $\mathrm{H}_{3} \mathrm{RITA}$. 


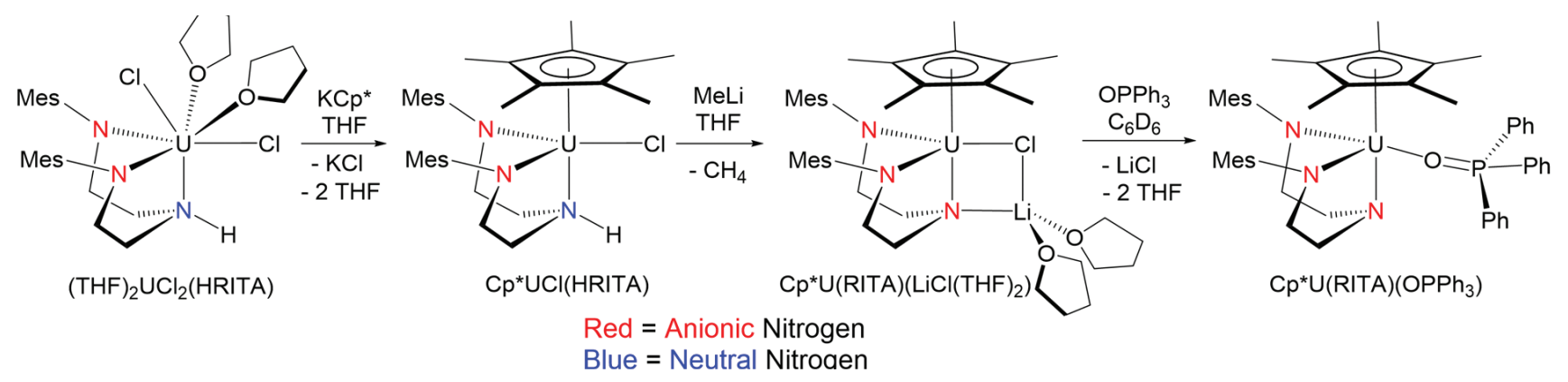

Scheme 2. Synthesis of $C p^{*} U C l(H R I T A), C p^{*} U(R I T A)\left(\mathrm{LiCl}(T H F)_{2}\right)$, and $C p^{*} U(R I T A)\left(O P P h_{3}\right)$.

organometallic containing peak is observed at $13.26 \mathrm{ppm}$ and is attributed to the $\mathrm{Cp}^{*}$.

To date, complexes (THF) $\mathrm{UCl}_{2}$ (HRITA), $\left(\mathrm{Ph}_{3} \mathrm{PO}\right)$ $\mathrm{UCl}_{2}$ (HRITA), and Cp*UCl(HRITA) have been characterized by electronic absorption spectroscopy. In this technique, a sample is dissolved in a solvent, and analyzed by passing light of different wavelengths through it. Based on the energy of the light, different electronic transitions are observed, making it possible to gain insight into the electronic structure. For these uranium complexes, their spectra are displayed in Figure 5. By visual inspection, their colors are light green, green-yellow, and dark orange. As a result, for both (THF) $\mathrm{UCl}_{2}$ (HRITA) and $\left(\mathrm{Ph}_{3} \mathrm{PO}\right) \mathrm{UCl}_{2}(\mathrm{HRITA})$, we would expect a visible absorbance near $400 \mathrm{~nm}$. Although there are no significant absorptions in the visible region for this complex, the observed color is likely due to a weakly intense shoulder located at about $420 \mathrm{~nm}$. Similarly, for $\mathrm{Cp}^{*} \mathrm{UCl}(\mathrm{HRITA})$, the dark orange color

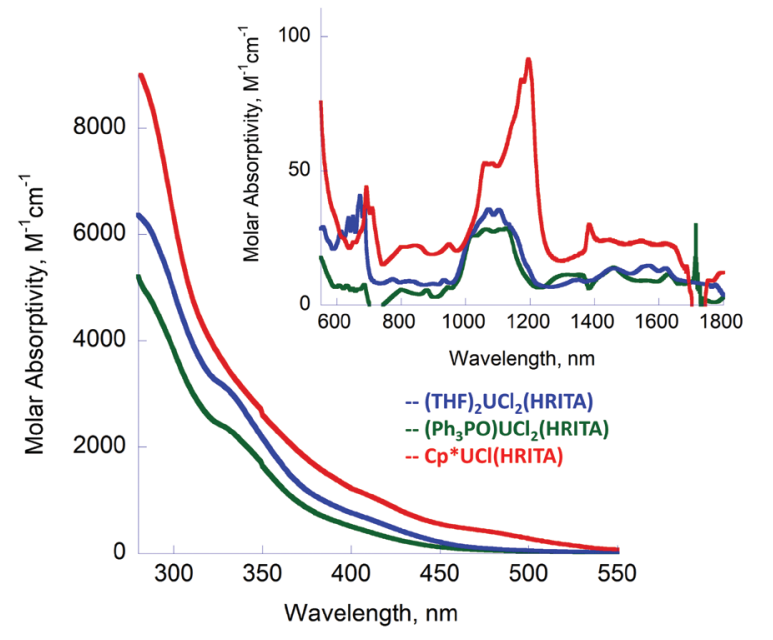

Figure 5. Electronic absorption spectra of (THF) ${ }_{2} \mathrm{UCl}_{2}(\mathrm{HRITA})$ (blue), ( $\left.\mathrm{Ph}_{3} \mathrm{PO}\right) \mathrm{UCl}_{2}(\mathrm{HRITA})$ (green), and Cp*UCI(HRITA) (red) recorded from 1800 to $280 \mathrm{~nm}$ in THF solvent at ambient temperature. of the complex is due to a weakly intense shoulder located near $490 \mathrm{~nm}$. For all species, there appears to be a strong absorbance present near the ultraviolet region, likely due to the many aromatic moieties in the molecules. Additionally, all species show weakly intense but sharp $\mathrm{f}-\mathrm{f}$ transitions located from 600 to $1800 \mathrm{~nm}$. For (THF) $)_{2} \mathrm{UCl}_{2}(\mathrm{HRITA})$ and $\left(\mathrm{Ph}_{3} \mathrm{PO}\right)$ $\mathrm{UCl}_{2}$ (HRITA), these range in intensities from $\sim 10$ to $40 \mathrm{M}^{-1} \mathrm{~cm}^{-1}$, while for $\mathrm{Cp} * \mathrm{UCl}(\mathrm{HRITA})$ they range from $\sim 20$ to $100 \mathrm{M}^{-1} \mathrm{~cm}^{-1}$. These observations are consistent with a uranium(IV) oxidation state, and are similar to those observed for $\left[\mathrm{Li}(\mathrm{DME})_{3}\right]$ $\left[\mathrm{U}\left(\mathrm{CH}_{2} \mathrm{SiMe}_{3}\right)_{5}\right]$ and $\left[\mathrm{K}(\mathrm{THF})_{\mathrm{x}}\right]_{2}\left[\mathrm{U}\left(\mathrm{CH}_{2} \mathrm{Ph}\right)_{6}\right]$, which were synthesized by the Hayton lab (Fortier, Melot, Wu, \& Hayton, 2009).

\section{CONCLUSION AND FUTURE STUDIES}

In summary, we have been able to synthesize a variety of molecules containing a tridentate redox-innocent triamine ligand. Metallation of the deprotonated ligand, $\mathrm{K}_{2} \mathrm{HRITA}$, with $\mathrm{UCl}_{4}$ afforded (THF) ${ }_{2} \mathrm{UCl}_{2}$ (HRITA) as well as $\left(\mathrm{Ph}_{3} \mathrm{PO}\right)$ $\mathrm{UCl}_{2}$ (HRITA) by ligand substitution. Following addition of the cyclopentadienyl ligand to form $\mathrm{Cp} * \mathrm{UCl}(\mathrm{HRITA})$, full deprotonation of the ligand was achieved through the use of the strong base, methyllithium. The final products formed, $\mathrm{Cp} * \mathrm{U}(\mathrm{RITA})\left(\mathrm{LiCl}(\mathrm{THF})_{2}\right)$ and $\mathrm{Cp} * \mathrm{U}(\mathrm{RITA})$ $\left(\mathrm{OPPh}_{3}\right)$, both bear a trianionic nitrogen-based ligand. We anticipate that these species will show unique reactivity toward a variety of organic molecules in the effort to further our understanding of organometallic processes of the f-block elements, specifically uranium. Future studies will focus on the addition of a variety of substrates to $\mathrm{Cp} * \mathrm{U}$ (RITA) $\left(\mathrm{LiCl}(\mathrm{THF})_{2}\right)$ and $\mathrm{Cp} * \mathrm{U}(\mathrm{RITA})\left(\mathrm{OPPh}_{3}\right)$ including, but not limited to, alcohols (R-OH; $\mathrm{R}=$ carbon chain), amines ( $\left.\mathrm{R}-\mathrm{NH}_{2}\right)$, alkylhalides ( $\mathrm{R}-\mathrm{X} ; \mathrm{X}=$ halogen), and alkynes ( $\mathrm{R}-\mathrm{C} \equiv \mathrm{C}-\mathrm{R})$. These various substrates will allow for direct correlation of the reactivity of our system versus its more thoroughly studied transition metal counterparts. 


\section{ACKNOWLEDGMENTS}

The authors acknowledge funding from the Division of Chemical Sciences, Geosciences, and Biosciences, Office of Basic Energy Sciences, Heavy Elements Chemistry Program of the U.S. Department of Energy through Grant DE-AC0212ER16328 (SCB).

\section{REFERENCES}

Fortier, S., Melot, B. C., Wu, G., \& Hayton, T. W. (2009). Homoleptic uranium(IV) alkyl complexes: Synthesis and characterization. Journal of the American Chemical Society, 131(42), 15512-15521. http://dx.doi.org/10.1021/ja906516e

Jantunen, K. C., Haftbaradaran, F., Katz, M. J., Batchelor, R. J., Schatte, G., \& Leznoff, D. B. (2005). Synthesis and structure of diamido ether uranium(IV) and thorium(IV) halide "ate" complexes and their conversion to salt-free bis(alkyl) complexes. Dalton Transactions, 34, 3083-3091. http://dx.doi.org/10.1039/B506180F

Kiernicki, J. J., Cladis, D. P., Fanwick, P. E., Zeller, M., \& Bart, S. C. (2015). Synthesis, characterization, and stoichiometric U-O bond scission in uranyl species supported by pyridine(diimine) ligand radicals. Journal of the American Chemical Society, 137(34), 11115-11125. http://dx.doi.org/10.1021/jacs.5b06217

Kiernicki, J. J., Harwood, J. S., Fanwick, P. E., \& Bart, S. C. (2016). Reductive silylation of Cp*UO2(MesPDIMe) promoted by Lewis Bases. Dalton Transactions, 45, 3111-3119. http://dx.doi.org/10.1039/C5DT04776E
Liang, L.-C., Schrock, R. R., Davis, W. M., \& McConville, D. H. (1999). Synthesis of group 4 complexes that contain the diamidoamine ligands, $[(2,4,6-\mathrm{Me} 3 \mathrm{C} 6 \mathrm{H} 2 \mathrm{NCH} 2 \mathrm{CH} 2) 2 \mathrm{NR}] 2-; \mathrm{R}=\mathrm{H}$ or $\mathrm{CH} 3$ ), and polymerization of 1-hexene by activated [Mes2N2NR]ZrMe2 complexes. Journal of the American Chemical Society, 121(24), 5797-5798. http://dx.doi. org/10.1021/ja983636n

McMullough, L. G., Turner, H. W., Andersen, R. A., Zalkin, A., \& Templeton, D. H. (1981). Preparation and crystal structure of the 1,2-dimethoxyethane complex of bis[bis(trimethylsilyl)amido]dichlorouranium(IV). Inorganic Chemistry, 20(9), 2869-2871. http://dx.doi. org/10.1021/ic50223a025

Schrock, R. R., Lee, J., Liang, L.-C., \& Davis, W. M. (1998). The synthesis and structures of tantalum complexes that contain a triamido or diamidoamine ligand. Inorganica Chimica Acta, 270, 353-362. http://dx.doi.org/10.1016/ S0020-1693(97)05869-6

Thomson, R. K., Scott, B. L., Morris, D. E., \& Kiplinger, J. L. (2010). Synthesis, structure, spectroscopy and redox energetics of a series of uranium(IV) mixed-ligand metallocene complexes. Comptes Rendus Chimie, 13, 790-802. http://dx.doi.org/10.1016/j.crci.2010.04.008

Wolfe, J. P., Wagaw, S., \& Buchwald, S. L. (1996). An improved catalyst system for aromatic carbonnitrogen bond formation: The possible involvement of bis(phosphine) palladium complexes as key intermediates. Journal of the American Chemical Society, 118(30), 7215-7216. http://dx.doi.org/10.1021/ ja9608306 